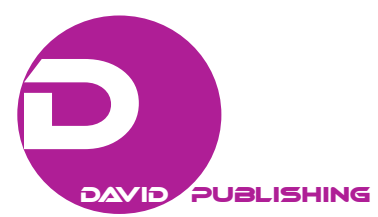

\title{
A Triangular Model for Social Work Groups: Teaching the Forgotten Practice Modality
}

\author{
Billy P. Blodgett, Henry Poduthase \\ West Texas A\&M University, Texas, USA
}

\begin{abstract}
Social Work students typically enroll in the required practice methods courses that are specified by the Council on Social Work Education. At least in the majority of BSW Programs, these practice methods courses are divided into micro-level and macro-level sequences. Individual and family systems are covered in the former sequence, while communities and organizations are the systems of focus in the latter sequence. The group system is often minimized and/or completely ignored in the process, even though there may be some reference made to groups in both practice methods sequences. Consequently, the mezzo-level system of groups is only given "lip-service" in the dyadic division of micro and macro-level practice. Furthermore, students often do not have the opportunity to practice in group settings, much less, develop competency in these professional venues. This paper describes a teaching format used in a BSW Program in an effort to ensure student competency as required in a Groups Practice course. The triangular model includes: (1) Classroom teaching of theory; (2) Practice of group dynamics; and (3) Supervision by instructors and MSW students.
\end{abstract}

Keywords: groups, teaching, practice, supervision, monitoring, evaluation

\section{Introduction}

In most academic social work curriculums, the core elements of HBSE, Welfare, Research, Practice, and Field Practicum are emphasized. In terms of Practice, it appears that most curriculums divide Practice into an artificial dichotomy: Micro and Macro. Micro practice is often perceived to be individual and family intervention, whereas Macro practice concerns itself with organizational and community systems. Students then tend to gravitate towards the Micro track, as most view themselves as "practitioners", not realizing that Practice is multi-faceted.

Systems Theory is then integrated throughout the social work curriculum, as the dimensions of individual, family, group, organizations, and communities are targeted for change. What is obviously minimized here (in the micro-macro concept) is the system of "groups". This designated "mezzo" system is often given "lip-service" within the teaching pedagogy. Consequently, students often do not have the opportunity to learn group theories, techniques, and general competencies when it comes to practice.

This paper describes how at least one university addresses this predicament in its accredited BSW program. It is a testament in itself that a specific course entitled "Group Processes" is even offered and required in its

Billy P. Blodgett, Ph.D., Assistant Professor of Social Work, Department of Psychology, Sociology, and Social Work, West Texas A\&M University.

Henry Poduthase, Ph.D., Assistant Professor of Social Work, Department of Psychology, Sociology, and Social Work, West Texas A\&M University. 
professional degree plan. Students are not only provided with didactic theoretical content in the course, but are also required to demonstrate group-practice skills with actual clients in a community agency as part of the learning agreement. This unique experience is thoroughly discussed here in hopes that other institutions of higher learning can embellish on this opportunity that is offered to students, clients, and social service agencies.

\section{Definitions and History}

Group Work can be defined as a goal-directed activity where two or more people are interacting with each other and influencing each other (Shaw, 1981). Brown (1991, p. 3) conceptualized a group as "a small face-to-face collection of persons who interact to accomplish a purpose". Another definition (D. W. Johnson \& F. P. Johnson, 2006, p. 4) suggests that a group is "two or more individuals in face-to-face interaction, each aware of his or her membership in the group, each aware of the others who belong to the group, and each aware of their positive independence as they strive to achieve mutual goals". Groups can also be formed for the purposes of support, education, growth, therapy, socialization, and self-help (Toseland \& Rivas, 2012).

Within the social work profession, the history of group intervention has waxed and waned in terms of interest, professional literature, and practice. Social workers formed the American Association for Group Work in the 1930's, and this organization later merged with other movements to form the National Association of Social Workers in the mid-1950s (Ephross \& Vassil, 2005). Hutchison (2011) noted that group work became popular in clinics and hospitals during World War II, and again was emphasized in educational settings during the 1960s. However, as the social work profession began to emphasize clinical work with individuals and families throughout the next decade, interest in group work declined. Now with the advent of managed care and mutual aid modalities, the group system has been revised for both therapeutic and cost-saving purposes. Unfortunately, schools of social work are not always training its students to develop skills in this emerging setting. As an exception, the following content will dissect a course entitled "Group Processes" (SOCK 4310), which one university is teaching as part of its required BSW curriculum. A triangular model of approach will be presented in an effort to describe content, process, and monitoring/evaluation.

\section{Content}

A number of excellent social work texts on group work have been published and adopted by various programs in schools of social work. Moreover, even more authors have chosen to include a chapter or two on group work within micro and macro texts. This content is usually covered within a month at best, and more attention is paid to therapeutic techniques with individuals/families or with intervention models toward organizations/communities. For the purposes of this course in question, the text entitled An Introduction to Group Work Practice (Toseland \& Rivas, 2012) is the main source for theoretical content.

For the first two months of the course, the following topics are discussed in lecture and discussion formats: typologies of treatment and task groups, values and ethics, historical and theoretical developments, group dynamics (stages, communication patterns, cohesion, culture, conformity, groupthink), as well as leadership and co-leadership styles. Additionally, planning, monitoring, assessment/evaluation, and termination are all included. Students are tested on at least three occasions to determine if transfer of knowledge has been successful. Videos, live demonstrations, modeling, and role playing are all utilized in an effort to immerse students in the many complex facets of group intervention. Since this is an undergraduate course, students are not expected to be therapists. Rather, they are taught to see themselves as group facilitators. They are not 
experts, but are considered collaborators. A strengths perspective is emphasized not only for their own reflection, but for potential group members as well. "A strengths-based orientation is respectful of the individual, one of social work's prime values, in that it recognizes people's capacities and focuses on the development of environmental supports rather than taking a pathological view of the individual" (Corcoran, 2009 , p. 2). Content, as described above, serves as the foundation from which the triangular model can be further constructed.

\section{Process}

Usually within the first three weeks of the course, students are randomly selected to form groups of three-five members, depending on the size of the class (typically 15-25 students). These groups stay together throughout the semester, and often are asked to sit together for much of the didactic content. In the syllabus, it is explained that beginning on the third month, students will be facilitating groups at a local agency of their choice. They are expected to complete six hours of practice, usually conducted for four 90-minute sessions. Agencies that have been selected by students include schools, boys and girls clubs, residential programs for children, faith city missions, half-way houses for women who have been incarcerated, group homes for homeless men, and outpatient psychiatric programs. Consequently, much planning is required before a group session ever begins. Such planning includes contacting the administrator of the agency for permission, undergoing police checks if required, developing the days and times for each session to ensure that each group member can attend all meetings, as well as constructing goals, content, exercises, and means of evaluation.

Since the university currently utilizes the computer class platform of "Angel”, this course contains drop boxes for students to submit assignments. Such drop boxes include: (1) group proposal; (2) plan for evaluation; and (3) progress notes. Proposals have to be preapproved by the instructor prior to the first session. A plan for evaluation is also required, so students have to be familiar with both qualitative and quantitative research. Finally, each student from each group is required to write a one-page progress report within 48 hours after the conclusion of every session (four progress notes in all for each student). These reports include summations, impressions, and reflections in a process-oriented manner. In the triangular model that defines this paper, it is this "process" that serves as one important side of the metaphoric symbol.

\section{Monitoring/Evaluation}

"Increasingly in social work and allied disciplines, there has been a push toward accountability and empirically validated practice" (Toseland \& Rivas, 2012, p. 421). This statement is certainly true when it comes to teaching Group Processes. Progress notes that were previously mentioned are good ways to provide subjective impressions of the group process. However, each group and each member needs to have a more objective method in evaluating what they do. The term "monitoring" is typically used when discussing evaluations. Some authors differentiate the two, while others simply treat them as synonymous. In actuality, both are significant factors in terms of completing the triangle for this course. For this purpose of this paper, "monitoring" is considered a process, while "evaluation" is considered an outcome.

There are two ways in which the work of the student groups is monitored. First, the write-up and submission of progress notes (mentioned before) is one method by which groups are monitored. Each student report is confidential, so no other group member can see what has been submitted. The instructor can then give feedback to each student, as well as, make general remarks to the group as a whole, based on report trends. 
Since each student has to submit notes within 48 hours after the completion of each group, recollections and impressions are still vivid.

Second, each group is supervised from one to three different people. The instructor is first responsible to attend at least one live session of each group. Notes are taken, feedback is given, and discussions are conducted. The agency caseworker, supervisor, administrator, or some other significant employee usually sits in and observes the process as well. Also, MSW students often attend group sessions, and are assigned supervisory responsibilities as a requirement for one of their own courses. Consequently, this kind of supervision ensures yet a second triangle within the course framework.

The final evaluation also is a three-part process. As stated earlier, each group has to submit an evaluation plan that is linked to the established goals. The plan may involve an evaluation form that is administered after each session and/or a final evaluation form at the end of the fourth group session. A second requirement is that each student has to write a short paper near the end of the semester about his/her group experience. This is a compilation of progress reports, impressions, summations, and final evaluation that is objectively obtained. Third, rather than taking a final exam on the last week of class, each group is expected to make a half-hour presentation on their group experiences. This includes power points, pictures, and other material that was utilized during their four-week experience.

Each and every requirement is worth a certain amount of points. Points accumulate from both individual and group responsibilities. Specifically, the grade and point distributions are depicted as follows in Table 1.

Table 1

Evaluation Criteria: Course Requirements and Grading

\begin{tabular}{|l|l|}
\hline Individual Assignments: & \\
\hline Exams: 3@ 100 points each & 300 \\
\hline Weekly Progress Reports: 4 @ 50 points each & 200 \\
\hline Final Evaluation Report \& Assessment Paper: & 100 \\
\hline Class Attendance/Participation & 100 \\
\hline TOTAL INDIVIDUAL POINTS AVAILABLE: & 700 \\
\hline Group Assignments: & \\
\hline Group Proposal & 100 \\
\hline Group Evaluation Plan & 100 \\
\hline Final Presentation: & 100 \\
\hline TOTAL GROUP POINTS AVAILABLE: & 300 \\
\hline TOTAL POINTS AVAILABLE: & 1000 \\
\hline
\end{tabular}

Notes. $930-1000=\mathrm{A} ; 820-929=\mathrm{B} ; 710-819=\mathrm{C} ; 600-709=\mathrm{D} ; 599$ or below $=\mathrm{F}$.

\section{Summation and Conclusion}

It comes as no surprise that the final side of the triangular model is "monitoring and evaluation". As an instructor, this course needs to be monitored and evaluated after each semester. Fortunately, there are always two instructors that teach different sections of this course every semester. Not only do these instructors meet together several times throughout the semester as the classes are being taught, but a weekly faculty meeting ensures that each course in the curriculum is being discussed while it is being taught. Teaching styles vary, as do the "cultures" and "personalities" of each class. What may work well for one instructor may not necessarily be conducive to the teaching style of the other instructor. Likewise, what goes well for one semester may not go 
so well for the next. Like any system, each course, class session, student and instructor is a living, breathing mechanism.

Through continual assessment, this triangular model may require expansion to simulate a square or other more complex symbol. Interestingly, symbolic interaction and systems theory become two important theoretical models that guide this course. Perfection is never achieved in the course of teaching practice content. Fortunately, for many students, this particular course is often cited as the most meaningful experience throughout our social work curriculum. Future clients will ultimately be the benefactors of any practice competencies achieved and demonstrated by our students.

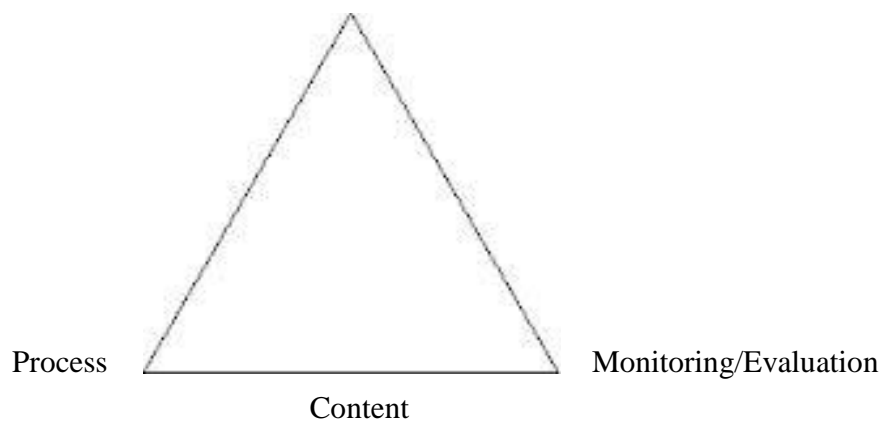

Figure 1. The triangular model.

\section{References}

Brown, L. N. (1991). Groups for growth and change. New York: Longman.

Corcoran, J. (2009). Groups in social work: A work book. Boston: Pearson.

Ephross, P. H., \& Vassil, T. V. (2005). Groups that work: Structure and process. New York: Columbia University Press.

Hutchison, E. D. (2011). Dimensions of human behavior: Person ad environment (4th ed.). Thousand Oaks, CA: Sage.

Johnson, D. W., \& Johnson, F. P. (2006). Joining together: Group theory and group skills (9th ed.). Boston: Allyn and Bacon.

Shaw, M. (1981). Group dynamics: The psychology of group behavior (3rd ed.). New York: McGraw-Hill.

Toseland, R. W., \& Rivas, R. R. (2012). An introduction to group work practice (7th ed.). Boston: Allyn and Bacon. 